\title{
A novel implantable device for a minimally invasive surgical treatment of obstructive sleep apnea: design and preclinical safety assessment
}

This article was published in the following Dove Press journal:

Nature and Science of Sleep

20 July 2016

Number of times this article has been viewed

\section{Edward Gillis \\ Charles Rampersaud \\ Emmanuelle Pease \\ Paul Buscemi}

ReVENT Medical, Inc., Newark, CA, USA
Correspondence: Edward Gillis ReVENT Medical, Inc., Suite 350, 39899 Balentine Drive, Newark, CA 94560, USA

Tel +I 5102790700

Email ed@reventmedical.com
Background: In obstructive sleep apnea (OSA), occlusion of the upper airway by soft tissue causes intermittent hypoxemia and can have serious sequelae. A novel implantable medical device for OSA is composed of a linear silicone elastic element held in an extended state by a bioabsorbable external sheath. The implant is delivered to the tongue base or soft palate via a minimally invasive approach. Normal tissue healing anchors the device at the attachment points before the bioabsorbable material dissolves and the elastic element contracts to stabilize the surrounding tissue.

Methods: Device prototypes were evaluated in multiple investigations: 1) a finite elements analysis model simulated the movement of the tongue base during sleep with and without the implant; 2) dynamic mechanical testing simulated 10 years' normal use; 3 ) cadaveric implantations were conducted; 4) an ovine study in which implants of varying design were evaluated via gross pathology and histological assessment; and 5) a canine study in which implants of varying design in the tongue base and soft palate were evaluated via gross pathology and histological assessment.

Results: 1) The implant was capable of reducing $~ 95 \%$ of tongue base movement during simulated sleep; 2) implants remained intact throughout the testing with no evidence of creep fatigue or change in dynamic modulus; 3 ) the device could be reliably deployed in the desired placement locations and was appropriate for various anatomies; and 4) all implants were well tolerated through 1 year, with minimal inflammatory responses.

Conclusion: This new minimally invasive device for OSA has been demonstrated, through various bench and animal testing, to be safe, well tolerated, suitable for long-term use, and to function as intended. No adverse health consequences were observed in the animals, and histological evaluation indicated good healing. This study establishes proof of concept and supports human trials.

Keywords: obstructive sleep apnea, implantable device, surgical treatment, breathing, sleep, tongue

\section{Introduction}

Obstructive sleep apnea (OSA) is a condition characterized by repeated upper airway obstruction during sleep, potentially resulting in intermittent hypoxemia and arousals from sleep. ${ }^{1}$ OSA results from collapse of the soft palate and/or tongue base during sleep. The consequences of untreated OSA include sudden death, ${ }^{2}$ hypertension, ${ }^{3}$ stroke, ${ }^{4}$ coronary artery disease and congestive heart failure, ${ }^{5}$ noninsulin-dependent diabetes, ${ }^{6}$ depressive symptoms, ${ }^{7}$ and decreased quality of life. ${ }^{8}$ OSA is common, affecting an estimated range of $3 \%-7 \%$ of adults. ${ }^{9}$ 
Recent studies suggest that a majority of patients with OSA have obstruction occurring at both the palate and tongue base. ${ }^{10}$ The current standard of care for OSA is treatment with continuous positive airway pressure (CPAP), which prevents collapse of the airway. ${ }^{11}$ Although usually efficacious, ${ }^{12}$ at least $40 \%$ of patients are unable to tolerate it. ${ }^{13}$ Patients who are unable to use CPAP may consider other options, including surgery. Most surgical treatments do not require daily usage of any equipment, thus mitigating the lack of compliance associated with CPAP. Available evidence suggests that successful surgical treatment that improves OSA also lowers cardiovascular risk. ${ }^{14,15}$ Multiple surgical options exist, including reduction of nasal obstruction, oropharyngeal enlargement (uvulopalatopharyngoplasty, expansion sphincter pharyngoplasty, or transpalatal advancement pharyngoplasty), hypopharyngeal dilation, and maxillomandibular advancement. ${ }^{16}$ All are irreversible and carry significant risk of morbidity. Unfortunately, current surgical approaches are limited by the technical difficulty of performing the procedures, the potential for serious perioperative complications, and side effects of the procedures, particularly related to dysfunction of speech and swallowing, with a reported incidence as high as $60 \% .{ }^{17}$ Furthermore, to be effective, surgical treatment must address all potential sources of upper airway obstruction, principally collapse of the soft palate and/or tongue base during sleep. Based on the clinical need to reduce or eliminate OSA and its limited treatment options, there is a significant need for less invasive and more effective surgical treatment for OSA.

A novel medical device has been designed to be surgically implanted into the tongue base and palate via a minimally invasive approach in order to prevent collapse of those tissues into the airway that can result in OSA. This study describes the studies that were conducted to refine the prototype's design and confirm critical attributes prior to device evaluation in a human population. The device was evaluated via multiple methods: computer modeling, mechanical and fatigue testing, cadaveric implantation tests, and preclinical assessments in animal models. Stability, safety, and performance data are presented.

\section{Methods}

\section{Device and implantation}

Prototype devices were developed. Critical attributes considered during device design included long-term biocompatibility of all materials, lifetime stability of the device elements, ease of implantation, ease of removal (if desired), and most importantly, sufficient strength to provide soft tissue support but sufficient elasticity to allow for normal speech and swallowing without any awareness of the device. Additional design considerations included ease and reproducibility of manufacture, use of well-accepted and readily available biomaterials, and compatibility of the device with other OSA interventions.

The initial design concept consisted of a linear silicone elastic element wrapped with a bioabsorbable material to keep it in an extended state. Attachment points at each end of the linear element allow self-anchoring of the device via the normal tissue healing response before the bioabsorbable material slowly dissolves, allowing the elastic element to contract and stabilize the surrounding tissue. Implant delivery involves a minimally invasive procedure of creating a tissue tunnel with the introducer (a stainless steel trocar) in the tongue base via submental incision or in the soft palate, and guiding the implant into place through the introducer via the pusher, a stainless steel rod that delivers the implant (Figure 1). A radiopaque marker at each end of the implant allows fluoroscopic visualization if desired.

\section{Ethics}

All regulations regarding the use of animals and cadavers in research were complied with and all appropriate approvals were obtained prior to study initiation. Ovine studies were conducted at University of Kaposvar, Hungary in the Department of Veterinary Medicine under the auspices of the Animal Use Committee at that University. The canine and cadaver studies were performed at American Preclinical Services (APS) in Minneapolis, Minnesota, USA, a facility with AAALAC accreditation and also licensed for studies with human cadavers. Animals were fed ad libitum and in compliance with Animal Regulation Conditions.

\section{Computer modeling}

Computer modeling was used to simulate the movement of the tongue base during sleep with and without the implant. Complexities are often encountered in modeling soft tissue. First, the tissue is nonlinear - it does not react in one-to-one correspondence of force and motion. Second, although excised tissue from many sources has been well characterized, obtaining precise physical parameters for in vivo tissue is difficult. Third, there is an unavoidable variability from individual to individual. However, these issues can be addressed using finite element analysis (FEA), a numerical method used to analyze stresses and strains within structures and other physical problems such as those involving heat, fluid flow, and electromagnetic systems. ${ }^{18}$ With accurate descriptors of material properties and loads, realistic representations can be obtained by solving a set of 


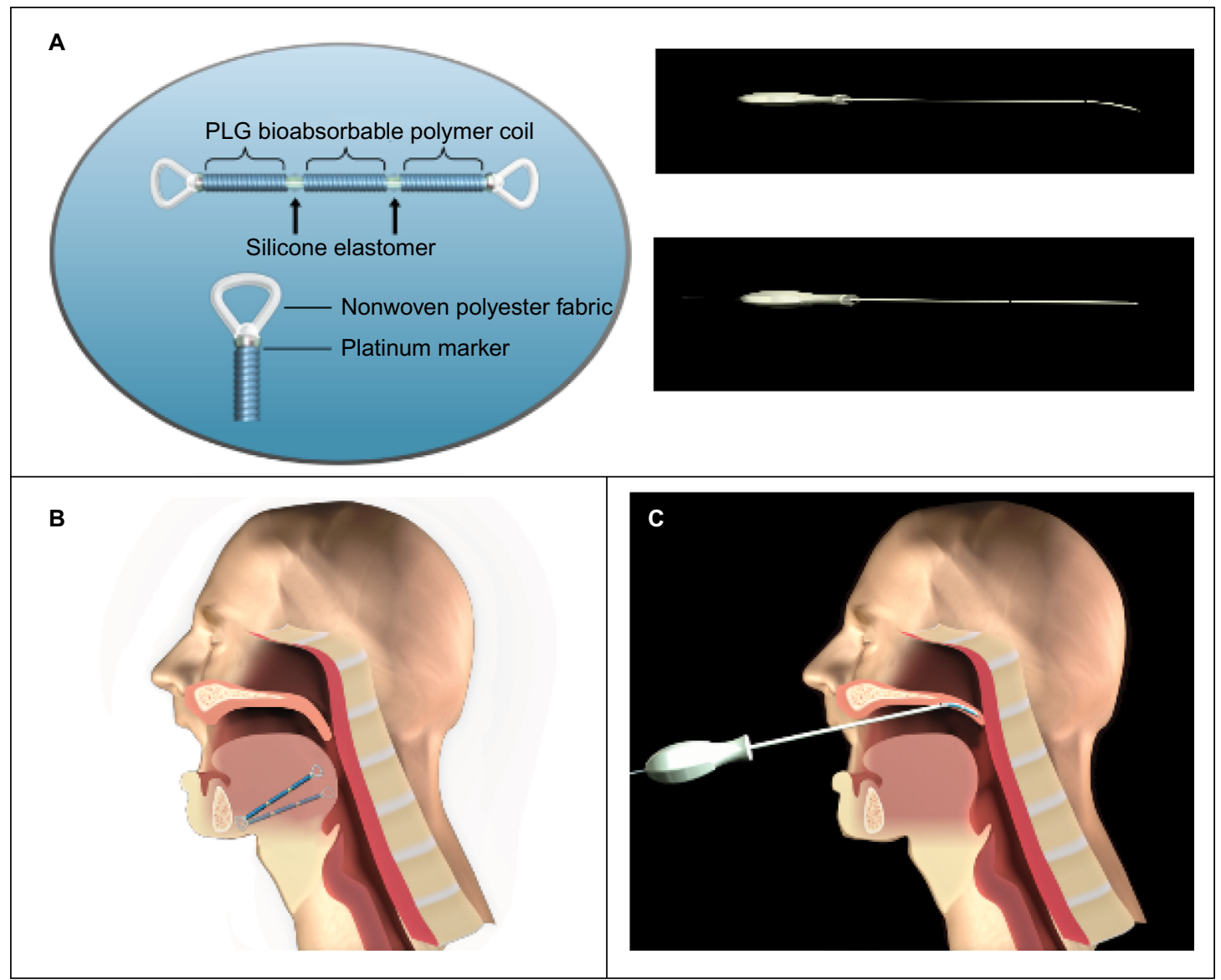

Figure I Schematic of the implant and delivery system.

Notes: The implant pictured has single-hole loop attachment points (A). The deployed implant is depicted in the tongue base (B) and soft palate (C), with the implant tool in situ for visualization of the delivery method).

Abbreviation: PLG, polylactide-co-glycolide.

equations representing the system in finite steps by dividing the physical representation into many small elements that can be more easily handled. FEA has been successfully applied to biological systems such as heart ${ }^{19}$ and other muscular systems, including the tongue..$^{20}$ Three-dimensional biomechanical models of the tongue have been used to study speech motor control and tongue motion, ${ }^{21}$ and this same FEA strategy were applied in the development of this study's human tongue construct and its life-like motion and muscle forces.

A construct of nonlinear components (Ogden parameters) ${ }^{18}$ representing the human tongue and its in vivo movement was developed based on MRI data and the equations of motion, which produce the stresses and strains of the mesh nodes. ${ }^{22-29} \mathrm{~A}$ quantitative description of the motion of the tongue can be made by tracking the displacement of one of the nodes. Using FEA, the physical displacement of the base of the tongue due to gravitational and sleep disordered breathing-related forces during sleep in the supine position was modeled as a control.
Implants (various lengths with an elastic modulus of $\sim 2 \mathrm{~N} / \mathrm{mm}^{2}$ ) were then introduced into the construct and forced to contract by $30 \%$. The physical displacement of the tongue base construct due to gravity was again observed; differences from the baseline displacements were attributed to the implant. The implant's insertion site, trajectory, and distal termination point were hypothesized to be relevant elements to the implant's effect on baseline displacement. Therefore, before contraction, implant placement was varied according to the implant's modeled insertion site and trajectory (a high sublingual site with a shallow angle of insertion vs a low submental site with an acute angle of insertion vs a midpoint of the two), and outcomes were compared. The effectiveness of the implant was also compared with the distal end terminating inside the tongue base away from the oropharyngeal surface of the tongue vs near to the oropharyngeal surface of the tongue (Figure 2). When deployed, the proximal end of the implant was assumed to be attached securely at the muscle/fascia, near the cutaneous surface. 
A

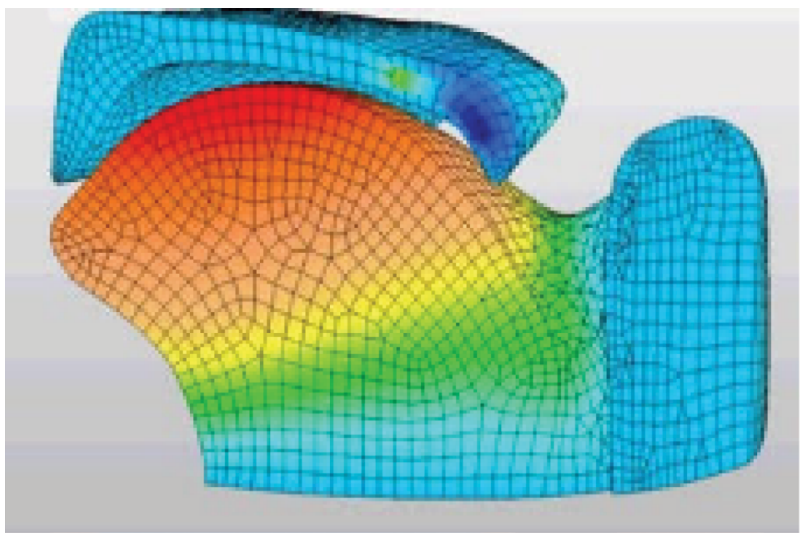

B

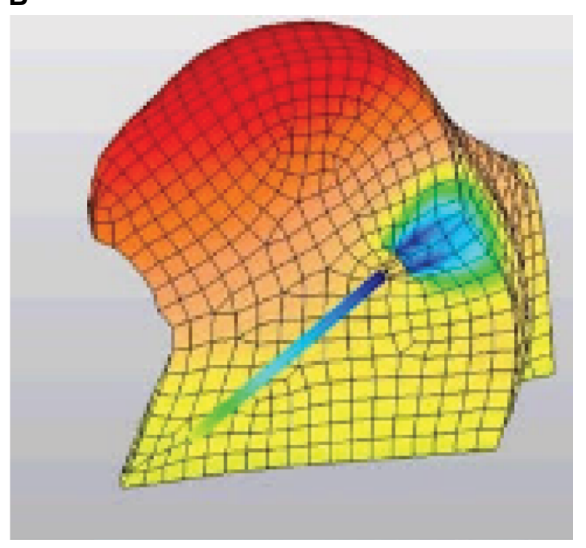

Figure 2 FEA model of the palate and tongue (A) and single-tongue implant (B).

Abbreviation: FEA, finite element analysis.

\section{Mechanical and fatigue testing}

Analysis of the soft palate and tongue base systems indicates that the highest stress on either system is caused by the force exerted on the tongue base during swallowing. During swallowing, the tongue moves in the posterior direction, closing the oropharynx. The range of dimensions for the oropharynx is estimated to be between $11 \mathrm{~mm}$ and $14 \mathrm{~mm},{ }^{30-34}$ and the movement of the tongue during swallowing is $\sim 10 \mathrm{~mm} .{ }^{35}$ Swallowing causes an implant positioned in the tongue base to stretch, thus imparting a tensile force on the implant. The maximum expected in vivo stretch of an implant was estimated based on the range of oropharyngeal dimensions documented in the literature, assuming a conservative model in which the implant stretches only along its axis and is rigidly fixed at the proximal position. An endurance value of $5,256,000$ stretch cycles was set based on the assumption of 1 swallow/min for 10 years. ${ }^{36}$

Mechanical testing was conducted after sterilization (irradiation) and simulated shipping. Aged ( 2 years) and nonaged implants were stretched in the axial direction to at least $150 \%$ of their fully contracted length. The implants were inspected for gross failure, defined as any failure or fracture that could be seen under $5 \times$ magnification. Displacement-controlled dynamic cycle fatigue testing was conducted on implants in $1 \times$ phosphate-buffered saline at $37^{\circ} \mathrm{C} \pm 3^{\circ} \mathrm{C}$ to simulate body conditions. The specimens were held by the test actuator and stretched axially to $150 \%$ of their contracted length. The specimens were then displaced cyclically by the actuator an additional fixed percentage at a cyclic displacement rate of $5 \mathrm{~Hz}$ using constant sinusoidal displacement amplitude control. Testing was terminated when the specimen reached the endurance value of 5,256,000 cycles or experienced failure. Before and after testing, the body length of each sample was measured, and the samples were subjected to a static axial tension test in which load and displacement data were collected. Every 100,000 cycles, dynamic stiffness (force/displacement) was calculated by capturing the peak and valley values from both the force and displacement sine waves. Every 1,000,000 cycles, macroscopic checks were performed and body length was measured. The failure mode of each specimen and the corresponding cycle count were recorded.

\section{Cadaveric testing}

Unfixed cephalous tissue specimens $(n=6)$ broadly characteristic of the target patient population (adults of normal-to-heavy body mass index with unremarkable oral cavities) were obtained. Testing was performed in a simulated surgical setting using tools and equipment commonly available to otorhinolaryngologists. Each of four experienced surgeons placed two implants in the tongue base and two implants in the soft palate via the methods described in the intended clinical instructions for use. Implant placement was fluoroscopically verified. Devices were inspected after implantation to ensure that device integrity was maintained throughout the procedure.

\section{Animal studies}

Sheep were selected for the tissue response study because the ovine mature skeletal striated muscle tissue approximates that of human and canine, and there is access to skeletal muscle relatively close to the cutaneous surface, thus facilitating relatively noninvasive implantation and removal of devices. Eight adult, experimentally naïve sheep of both sexes were anesthetized and received implants in the striated muscle tissue lateral to the spinal column. In all cases, animals were maintained under standard principles of laboratory animal 
care. Antibiotic treatment and analgesia were provided according to standard veterinary practice.

Each animal was implanted with 16 implants (four parallel rows of four implants). Multiple potential implant designs were tested with their locations randomized in each animal, employing:

- Varying attachment points: single-hole polyester-reinforced silicone loop, multiple-hole polyester-reinforced silicone, cylindrical woven polyester, or paddle-shaped nonwoven polyester.

- Varying erodible elements (ie, formulation of erodible bioabsorbable material): fast- or slow-eroding polylactide-co-glycolide (PLG).

The weight and behavior of each animal, as well as a CT scan of the implants, were recorded at baseline and monthly thereafter. At 1 month, 2 months, or 6 months postimplantation, animals were euthanized, and the devices and surrounding muscle tissue were excised en bloc. In addition, in two animals at 6 months postimplantation, tests of the strength of implant attachment were completed by exposing the center section of the implant and pulling on the implant ends. Implant/tissue samples were formalin fixed by immersion. Approximately half of the devices were examined for gross pathology and implant attachment quality, whereas the other half were submitted for histological evaluation. For this, longitudinal or transverse sections were taken at $5 \mu \mathrm{m}$ from the attachment element on each end of the implant and in the center of the implant through the erodible and elastic elements (two sections at each location). Sections were then dehydrated through gradient alcohol concentrations, cleared in xylene, stained with hematoxylin and eosin, and evaluated under light microscopy. Inflammation and resorption of the PLG erodible element were evaluated.

Dogs were selected to study the performance and local tissue response of the implant in the tongue base and soft palate because canine tongue muscle and soft palate tissue approximate human tissue, and there is excellent access to canine tongue and soft palate for implantation and implant site observation. Eighteen adult, experimentally naïve dogs of both sexes were anesthetized and implanted with 66 devices: 18 dogs received two implants $(28 \mathrm{~mm})$ in the soft palate, 14 dogs received two implants $(45 \mathrm{~mm})$ in the tongue, two dogs received one implant $(45 \mathrm{~mm})$ in the tongue, and two dogs did not receive any implants in the tongue. The singlehole attachment point design was used for all implants based on the outcomes of the ovine study ("Results" section).
Multiple potential implant designs were tested with their locations randomized in each animal, employing:

- Varying erodible elements (ie, varying formulation of the bioabsorbable material): fast-, medium-, or slow-eroding PLG.

- Varying hardness of silicone elastomer: high-, medium-, or low-durometer silicone.

At 2 months postimplantation, under anesthesia, tongue implants $(n=4)$ were removed in two canines to enable histological evaluation of the healing response. A subset of animals were euthanized at either 100 days, 180 days, or 365 days postimplantation and the implants $(n=26)$ or areas of previous implantation $(n=4)$ were analyzed by histological examination similar to that of the ovine study. Histology samples included high- and low-durometer silicone and all formulations of PLG. Inflammation was graded on a scale of $1-5$ ( $1=$ minimal and $5=$ overt abscess formation), and resorption of the PLG erodible element was graded on a scale of $0-4(0=$ none or negligible material persistent in tissue [completely resorbed] and $4=$ material persistent in tissue largely intact [nonresorbed]). Histological analysis was confirmed by an independent secondary reviewer. The remaining implants $(n=36)$ were evaluated for healing, gross pathology, and degree of attachment at various intervals between 2 months and 10 months postimplantation. Gross pathology samples included all silicone durometers and formulations of PLG.

\section{Statistical analysis}

FEA modeling was performed with Simulation Mechanical (Autodesk, San Rafael, CA, USA). Statistical analysis was performed with Microsoft Excel. Unless otherwise noted, data are presented as mean \pm SD.

\section{Results \\ Computer modeling}

Without an implant (control), the base of the tongue was modeled to move $7.3 \mathrm{~mm}$ toward the posterior pharyngeal wall due to the gravitational and breathing disorder-related forces when in the supine position. With an implant, the tongue displacement due to gravity was reduced. All permutations of implant insertion site and termination point of the distal end relative to the oropharyngeal surface of the tongue base showed some degree of displacement effectiveness. Insertion of the device from a sublingual site was least effective at reducing displacement, whereas a low 
submental insertion point was most effective. In addition, tissue stabilization was greatest when the distal end of the implant terminated near the surface of the tongue base (ie, traversing the entire tongue base instead of terminating in the belly of the muscle).

\section{Mechanical and fatigue testing}

Representative samples of new and aged implant specimens were stretched to failure in order to verify tensile holding force, elongation, and ultimate break force. All implants exceeded $150 \%$ elongation, with no observed failure as a result of the stretching until well past that level. For dynamic testing, all specimens remained intact through 5,265,000 stretch cycles, with no evidence of gross failure. There was no change in implant body length (no creep fatigue) throughout the 5,265,000 cycles. Additionally, there was virtually no change in dynamic modulus after the full test battery (Figure 3 ).

\section{Cadaveric testing}

Devices were successfully implanted in the tongue base and soft palate under fluoroscopic guidance. The device could be reliably deployed in the desired placement locations using the delivery system, it was not damaged by the deployment process, and its dimensions were shown to be appropriate for the target tissue in various anatomies.

\section{Animal studies Ovine study}

All implants were well tolerated by the animals. Both singlehole loop and paddle-shaped attachment points showed excellent encapsulation with fibrous tissue. The single-hole loop design was the easiest to remove by cutting either the loop material or the tissue column that had formed in the loop center. There was no need for additional dissection with the single-hole loop design, whereas removal of all

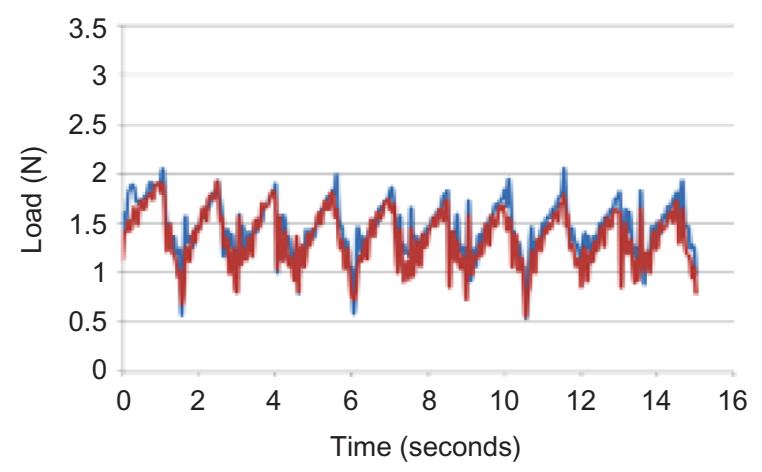

Figure 3 685207-FI pre- and postfatigue testing static conditioning test Note: The dynamic modulus of the implant was not affected by $5,260,000$ stretch cycles; values before (red) and after (blue) stretching were virtually identical.
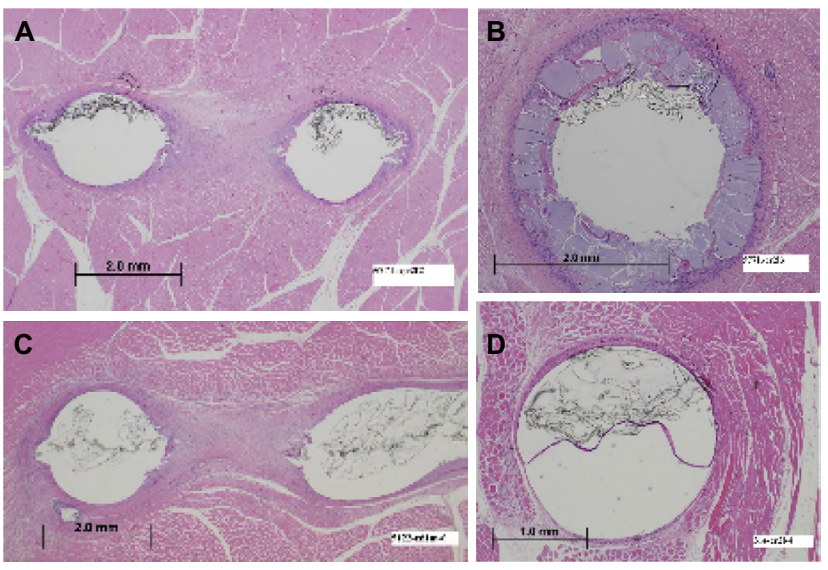

Figure 4 Exemplar histological samples: inflammatory response at the attachment points and middle of the linear component of the implants of sheep at 30 days and 60 days.

Notes: (A) Fibrous tissue fills the center hole of this device (center of image), bridging between muscle at the top and bottom of image. The two circular voids represent each side of the attachment point loop at 30 days. (B) This micrograph shows the typical 30-day reaction with the fast-eroding PLG; note that a residual PLG layer of $\sim 0.5 \mathrm{~mm}$ surrounds the device (void in center of image). There is mild accompanying foreign body-type inflammation directed at the PLG material, with a further encircling thin band of fibrous connective tissue. (C) There is mature fibrous tissue spanning the attachment opening and minimal inflammation at 60 days postimplantation. (D) There is a very thin circular layer of bland fibrous tissue encapsulating the contractile element at 60 days. No residual PLG is present and inflammation is insignificant.

Abbreviation: PLG, polylactide-co-glycolide.

other attachment element designs required some cutting of the adjacent tissue.

There was little inflammation at any of the attachment points or in the middle of the linear implant at any time points; inflammation was characterized by small numbers of multinucleated giant cells, consistent with a foreign body reaction (Figure 4). The fast-eroding PLG was significantly reabsorbed by 30 days and completely resorbed by 60 days, allowing the device to contract and exert tensile force on the target tissue. In contrast, evidence of resorption was absent in the implants with slow-eroding PLG (Table 1).

\section{Canine study}

Of the 66 devices implanted, there were three complications: one palate implant was missing at 3 weeks, one palate implant was exposed at 10 months, and one tongue implant showed an abscess around the implant at 3.5 months. All other implants were well tolerated by the animals and showed excellent healing and fibrous tissue attachment. There were minimal inflammatory responses at the ends or middle of the implants with the exception of the tongue implant that was assessed at 3.5 months and found to have an abscess with histological evidence of infection and a second tongue implant that was assessed at 6 months and found to have localized suppurative exudate at one end. 
Table I Single-hole silicone loop and paddle-shaped implant ends resulted in the best fibrous tissue attachment in lumbar muscle tissue in the ovine model

\begin{tabular}{|c|c|c|c|c|c|c|c|c|c|}
\hline \multirow[t]{2}{*}{ Days } & \multicolumn{4}{|c|}{ Attachment point evaluation } & \multicolumn{5}{|c|}{ Erodible element evaluation } \\
\hline & $\begin{array}{l}\text { Attachment } \\
\text { element } \\
\text { configuration } \\
\text { tested }\end{array}$ & $\begin{array}{l}\text { Number } \\
\text { of } \\
\text { implants } \\
\text { tested }\end{array}$ & $\begin{array}{l}\text { Fibrous tissue } \\
\text { anchoring of } \\
\text { attachment } \\
\text { point }\end{array}$ & $\begin{array}{l}\text { Inflammatory } \\
\text { response at } \\
\text { attachment } \\
\text { point }\end{array}$ & $\begin{array}{l}\text { PLG } \\
\text { erodible } \\
\text { element } \\
\text { tested }\end{array}$ & $\begin{array}{l}\text { Number of } \\
\text { implants } \\
\text { tested }\end{array}$ & $\begin{array}{l}\text { Degree of } \\
\text { hydrolysis and } \\
\text { bioabsorption } \\
\text { of erodible } \\
\text { element }\end{array}$ & $\begin{array}{l}\text { Contraction } \\
\text { of implant } \\
\text { and creation } \\
\text { of tensile } \\
\text { force }\end{array}$ & $\begin{array}{l}\text { Inflammatory } \\
\text { response at } \\
\text { middle of } \\
\text { implant }\end{array}$ \\
\hline \multirow[t]{5}{*}{30} & Single-hole & 5 & Excellent & Minor low & Fast & 12 & Significant & Significant & Negligible/ \\
\hline & silicone loop & & & grade/mild & eroding & & & & localized mild \\
\hline & $\begin{array}{l}\text { Multiple-hole } \\
\text { silicone }\end{array}$ & 4 & $\begin{array}{l}\text { Variable, } \\
\text { inconsistent }\end{array}$ & $\begin{array}{l}\text { Minor low } \\
\text { grade/mild }\end{array}$ & & & & & \\
\hline & $\begin{array}{l}\text { Polyester } \\
\text { cylindrical }\end{array}$ & 4 & $\begin{array}{l}\text { Variable, } \\
\text { inconsistent }\end{array}$ & Low grade & $\begin{array}{l}\text { Slow } \\
\text { eroding }\end{array}$ & 2 & Minimal & Absent & Minimal \\
\hline & Paddle shaped & 2 & Excellent & Minimal & & & & & \\
\hline \multirow[t]{4}{*}{60} & $\begin{array}{l}\text { Single-hole } \\
\text { silicone loop }\end{array}$ & 4 & Excellent & Low grade & $\begin{array}{l}\text { Fast } \\
\text { eroding }\end{array}$ & 12 & Complete & Significant & $\begin{array}{l}\text { Negligible/ } \\
\text { localized mild }\end{array}$ \\
\hline & $\begin{array}{l}\text { Multiple-hole } \\
\text { silicone }\end{array}$ & 3 & $\begin{array}{l}\text { Variable, } \\
\text { inconsistent }\end{array}$ & $\begin{array}{l}\text { Moderate } \\
\text { localized }\end{array}$ & & & & & \\
\hline & $\begin{array}{l}\text { Polyester } \\
\text { cylindrical }\end{array}$ & 6 & $\begin{array}{l}\text { Variable, } \\
\text { inconsistent }\end{array}$ & Low grade & $\begin{array}{l}\text { Slow } \\
\text { eroding }\end{array}$ & 2 & Minimal & Absent & Minimal \\
\hline & Paddle shaped & 2 & Excellent & Minimal & & & & & \\
\hline 180 & $\begin{array}{l}\text { Single-hole } \\
\text { silicone loop }\end{array}$ & 16 & Excellent & Minor localized & - & - & - & - & - \\
\hline
\end{tabular}

Notes: Fast-eroding PLG was fully resorbed within 60 days, allowing contraction of the implant and creation of tensile forces in the target tissues. There was little inflammatory response to the implant.

Abbreviation: PLG, polylactide-co-glycolide.

Table 2 For both tongue and soft palate implants in the canine model, there was little inflammatory response for either silicone durometer tested

\begin{tabular}{|c|c|c|c|c|c|c|c|}
\hline Days & Site & $\begin{array}{l}\text { Number of } \\
\text { implants }\end{array}$ & $\begin{array}{l}\text { PLG } \\
\text { erosion rate }\end{array}$ & $\begin{array}{l}\text { Silicone hardness } \\
\text { (durometer) }\end{array}$ & $\begin{array}{l}\text { Inflammation } \\
\text { (ends) }\end{array}$ & $\begin{array}{l}\text { Inflammation } \\
\text { (middle) }\end{array}$ & Erosion \\
\hline $100^{a}$ & Tongue & $\mathrm{I}^{\mathrm{a}}$ & Medium & Low & 0 & 2 & 2 \\
\hline $100^{\mathrm{a}}$ & Tongue & $\mathrm{I}^{\mathrm{a}}$ & Medium & High & 0 & 2 & 3 \\
\hline 100 & Tongue & I & Medium & Low & - & - & 3 \\
\hline 100 & Tongue & I & Medium & High & 2.5 & 2 & 3 \\
\hline 100 & Palate & I & Medium & Low & 1.5 & 2 & 3 \\
\hline 100 & Palate & I & Medium & High & 1.5 & 2 & 3 \\
\hline $180^{a}$ & Tongue & $2^{\mathrm{a}}$ & Medium & Low & 0.25 & 0.5 & I \\
\hline 180 & Tongue & 2 & Medium & High & 1 & 1 & 0 \\
\hline 180 & Tongue & 3 & Slow & Low & 2.2 & 1.67 & 0.67 \\
\hline 180 & Tongue & I & Slow & High & - & 2 & 2 \\
\hline 180 & Palate & 2 & Fast & Low & 1 & 1 & 0 \\
\hline 180 & Palate & 2 & Slow & Low & I & 1 & 3 \\
\hline 180 & Palate & 2 & Medium & Low & 1 & 1.5 & 1.5 \\
\hline 180 & Palate & 2 & Medium & High & 1.75 & 2 & 1 \\
\hline 365 & Tongue & 2 & Slow & Low & 1.5 & 0.5 & 0 \\
\hline 365 & Tongue & 2 & Fast & Low & 0.75 & 0 & 0 \\
\hline 365 & Palate & 2 & Slow & Low & 1.25 & 1.5 & 0 \\
\hline 365 & Palate & 2 & Fast & Low & 0 & 0 & 0 \\
\hline
\end{tabular}

Notes: All PLG materials were fully resorbed by 365 days postimplant. ${ }^{2}$ Histological analysis was completed on the implantation sites from which the implant had been removed at least 6 weeks prior. The - indicates samples with abscesses that were excluded from the data set for the purposes of statistical evaluation to remove bias from infection at the implant site, as the abscess was considered to be secondary to infection at the site and not a true reflection of the tissue response in the uncomplicated state. Inflammation was graded on a scale of $\mathrm{I}-5$ ( $\mathrm{I}=$ minimal and $5=$ overt abscess formation), and resorption of the PLG erodible element was graded on a scale of $0-4$ ( $0=$ none or negligible material persistent in tissue [completely resorbed] and 4= material persistent in tissue largely intact [nonresorbed]).

Abbreviation: PLG, polylactide-co-glycolide. 
The former device had been difficult to insert and the latter device was folded upon itself, suggesting difficulty in placement. Both of these infections were discovered upon histological evaluation; no evidence of infection in vivo had been apparent and as such no treatment (ie, antibiotics) had been given to the animals.

In general, inflammation was slightly greater around the erodible element relative to the attachment element, likely due to the PLG material stimulating a low-grade foreign body response as the material undergoes degradation and is removed from the tissue. Inflammation reduced over time. As expected, the rate of resorption of PLG material was a factor of its formulation (fast-, medium-, or sloweroding), and the degree of foreign-body inflammation was related to the amount of residual PLG in the target tissue. Although the fast-eroding PLG formulation was resorbed most quickly, all formulations of PLG material were fully resorbed, with no residual material, by 365 days. Virtually, all implants were well tolerated with no excessive inflammation or evidence of progressive or dissecting fibrosis after a year. Tensile strength (silicone durometer) appeared to have negligible effect on inflammation or PLG erosion (Table 2).

In four cases, the implant site was examined after the earlier removal of the implant followed by 6 weeks or 16 weeks of healing. All sites showed excellent healing. Fibrosis and inflammation were minor, and when noted, were limited to small regions of 2-3 mm, which would not be expected to have clinical consequences.

\section{Discussion}

A novel implanted device for the management of OSA was developed. The linear elastic implant is held in its extended state with bioabsorbable PLG; shortly after implantation in the tongue base or soft palate through a minimally invasive procedure, fibrous tissue infiltration into the ends of the implant anchors it in place. The PLG erodes over time, allowing the implant to contract and to apply tensile force onto the target tissue to retract the tongue and/or palate, expanding the oropharyngeal opening and/or reducing the degree of airway collapse during sleep. The implant is not expected to interfere with swallowing or other tongue function due to its flexibility and elasticity.

Computer modeling demonstrated that the implants are likely to be effective in vivo. When the FEA tongue model described in this study was used (which simulated gravitational and sleep disordered breathing-related forces during sleep in the supine position), the tongue base displaced
$7.3 \mathrm{~mm}$ into the oropharyngeal opening without an implant. Given that the glossopharyngeal airway has an average cross-section of $\sim 25 \mathrm{~mm}^{2},{ }^{37}$ this displacement would likely represent a clinically relevant occlusion. The introduction of a tongue base implant (in its fully attached and contracted state) applied an "internal retractor" to reduce the amount of tongue displacement. This is similar to the "pneumatic splinting" achieved by CPAP: at high pressure $\left(15 \mathrm{cmH}_{2} \mathrm{O}\right)$ the anterior-posterior midregion airway dimension is increased. ${ }^{38}$ The effectiveness of the implant, however, was strongly dependent on its physical location in the tongue base. We determined that implants deployed at a low submental entry point were more effective than those deployed from a high, sublingual entry point. Similarly, the ultimate site of the distal end of the implant was also important: tissue stabilization was greatest when the distal end of the implant terminated near the surface of the tongue base.

Most materials have a finite fatigue life when repeatedly stressed; this may eventually weaken the material and lead to failure. Therefore, mechanical testing was conducted to demonstrate the ability of a device to maintain its integrity during shipping, storage, implantation, and in vivo regarding its suitability as a long-term implant. Fatigue testing demonstrated that the fatigue life of the device is greater than the expected use life. For silicone polymers, failure may consist of rupture of the device or elongation due to creep fatigue. Static testing showed that implants were able to be stretched to at least $150 \%$ of their contracted length. Dynamic testing designed to approximate the stresses likely to be applied to the implant during swallowing was conducted for the equivalent of 10 years of usage. There was virtually no change in the implant's dynamic modulus after the full test battery, suggesting that the elasticity of the implant was fully maintained and that the implants are likely able to endure substantially longer cycles than tested. Together, this information suggests that deployed implants are unlikely to interfere with tongue motion and are also unlikely to fail due to tongue motion in vivo.

Placement of the implants into cadavers showed that the implants and the delivery system functioned as expected and were not damaged during the implantation process. Moreover, the cadaver work demonstrated that the device and delivery system were compatible with a broad range of human anatomies and with the anticipated user population, surgical environment, and surgical tools.

Testing in animals confirmed the feasibility of the implant process; very few difficulties were encountered. The ovine study involved implanting devices with various 
versions of attachment point structures into the dorsal trunk musculature, which approximates the tongue muscle in the humans and canines. The study showed that the implants are well tolerated and are easily anchored through normal tissue healing. The single-hole silicone loop attachment element proved to be the superior option, due to its greater consistency of attachment appearance relative to the other configurations in the histological analysis. The relatively large diameter hole in this configuration allows consistent attachment of fibrous tissue across the device, anchoring it into the muscle tissue. Furthermore, because this design was also found to be the easiest to manufacture, deploy, and remove after anchoring, it was selected for further study in canines. The canine study generated information regarding the local tissue response to devices sited in the tongue and palate. The study confirmed good biocompatibility, complete anchoring of the devices, easy removal (with no histological evidence of tissue trauma weeks later), and a low degree of inflammation. The results demonstrate that the implant is biocompatible in the tongue of dogs through 1 year.

In both animal studies, there was generally a minimal to mild low-grade foreign body-type response typical of any implanted device. The inflammation was localized to the device interface and considered to be fully biocompatible. Inflammation was slightly more prominent for devices with residual PLG material and appeared dependent on the amount of residual PLG persisting in the tissue. This is an expected consequence of bioabsorbable materials of this type and is transient. ${ }^{39}$ Indeed, where PLG was completely resorbed, inflammation was minimal. The medium-eroding PLG formulation emerged as the best option in the animal tests because it underwent significant hydrolysis and bioabsorption at the 30-day time point, as evidenced by the pronounced crumbling that was apparent histologically, and was essentially resorbed by 60 days. In contrast, the sloweroding PLG formulation persisted to a significant degree through 60 days and maintained most of the coiled structural integrity around the extended silicone elastomer, and the fast-eroding PLG formulation was completely resorbed at 60 days. Thus, the medium-eroding PLG allowed the tensile forces of the implant to be deployed as intended in the target tissue shortly after fibrous attachment was achieved. Silicone of different durometers and erodible elements of different PLG ratios all appeared equally safe and effective; differences in these materials are likely to show only minor variations in clinical results.

\section{Conclusion}

A new implantable device for the management of OSA has been demonstrated through computer modeling, mechanical bench testing, cadaver implantations, and animal implantations to be safe, well tolerated, and to function as intended. Stress testing supports the robustness of the device and suitability for long-term use. No adverse health consequences or other complications related to the implants were observed in the trunk of the sheep or in the tongue or palate of the dogs. Histological evaluation indicated good healing response for the tissue surrounding the implants. The device is implanted in a minimally invasive procedure and can be nontraumatically removed. This study establishes proof of concept as well as preclinical safety and stability, and suggests preliminary guidelines for implantation procedures in humans. The device has been adapted for human use; results of clinical studies are described separately.

\section{Acknowledgments}

This study was sponsored by ReVENT Medical, Inc. The authors thank American Preclinical Services (APS) for care of animals, Dr John Peauroi of VDx Veterinary Technical Services for histological evaluation, and the University of Kaposvar for care of animals. Additionally, the intellectual contribution of Allison Foster, $\mathrm{PhD}$, for writing assistance is recognized.

\section{Disclosure}

All authors are employees or consultants of ReVENT Medical, Inc. The authors report no other conflicts of interest in this work.

\section{References}

1. Green DE, Schulman DA. Obstructive sleep apnea and cardiovascular disease. Curr Treat Options Cardiovasc Med. 2012;12(4):342-354.

2. Young T, Finn L, Peppard PE, et al. Sleep disordered breathing and mortality: eighteen-year follow-up of the Wisconsin sleep cohort. Sleep . 2008;31(8):1071-1078.

3. Peppard PE, Young T, Palta M, Skatrud J. Prospective study of the association between sleep-disordered breathing and hypertension. $N$ Engl J Med. 2000;342(19):1378-1384.

4. Yaggi HK, Concato J, Kernan WN, Lichtman JH, Brass LM, Mohsenin V. Obstructive sleep apnea as a risk factor for stroke and death. $N E n g l$ J Med. 2005;353(19):2034-2041.

5. Shahar E, Whitney CW, Redline S, et al. Sleep-disordered breathing and cardiovascular disease: cross-sectional results of the sleep heart health study. Am J Respir Crit Care Med. 2001;163(1):19-25.

6. Reichmuth KJ, Austin D, Skatrud JB, Young T. Association of sleep apnea and type II diabetes: a population based study. Am J Respir Crit Care Med. 2005;172(12):1590-1595.

7. Peppard PE, Szklo-Coxe M, Hla KM, Young T. Longitudinal association of sleep-related breathing disorder and depression. Arch Intern Med. 2006;166(16):1709-1715. 
8. Baldwin CM, Griffith KA, Nieto FJ, O'Connor GT, Walsleben JA, Redline S. The association of sleep-disordered breathing and sleep symptoms with quality of life in the sleep heart health study. Sleep. 2001;24(1):96-105.

9. Punjabi NM. The epidemiology of adult obstructive sleep apnea. Proc Am Thorac Soc. 2008;5(2):136-143.

10. Kezirian EJ, White DP, Malhotra A, Ma W, McCulloch CE, Goldberg AN. Interrater reliability of drug-induced sleep endoscopy. Arch Otolaryngol Head Neck Surg. 2010;136(4):393-397.

11. Sullivan CE, Issa FG, Berthon-Jones M, Eves L. Reversal of obstructive sleep apnoea by continuous positive airway pressure applied through the nares. Lancet. 1981;1(8225):862-865.

12. Jenkinson C, Davies RJ, Mullins R, Stradling JR. Comparison of therapeutic and subtherapeutic nasal continuous positive airway pressure for obstructive sleep apnoea: a randomised prospective parallel trial. Lancet. 1999;353(9170):2100-2105.

13. Weaver TE, Grunstein RR. Adherence to continuous positive airway pressure therapy: the challenge to effective treatment. Proc Am Thorac Soc. 2008;5(2):173-178.

14. Kezirian EJ, Malhotra A, Goldberg AN, White DP. Changes in obstructive sleep apnea severity, biomarkers, and quality of life after multilevel surgery. Laryngoscope. 2010;120(7):1481-1488.

15. Peker Y, Hedner J, Norum J, Kraiczi H, Carlson J. Increased incidence of cardiovascular disease in middle-aged men with obstructive sleep apnea: a 7-year follow-up. Am J Respir Crit Care Med. 2002;166(2):159-165.

16. Soose RJ, Strollo PJ. Obstructive sleep apnea: surgery. In: Badr MS, editor. Essentials of Sleep Medicine: An Approach for Clinical Pulmonology. New York, NY: Humana Press; 2012:416.

17. Franklin KA, Anttila H, Axelsson S, et al. Effects and side-effects of surgery for snoring and obstructive sleep apnea-a systematic review. Sleep. 2009;32(1):27-36.

18. Hozapfel GA, Ogden RW, editors. Mechanics of Biological Tissue. Berlin: Springer-Verlag Berlin Heidelberg; 2006.

19. Guccione JM, Costa KD, McCulloch AD. Finite element stress analysis of left ventricular mechanics in the beating dog heart. $J$ Biomech. 1995;28(10):1167-1177.

20. Perrier P, Payan Y, Zandipour M, Perkell J. Influences of tongue biomechanics on speech movements during the production of velar stop consonants: a modeling study. J Acoust Soc Am. 2003;114(3):1582.

21. Gerard JM, Wilhelms-Tricarico R, Perrier P, Payan Y. A 3D dynamical biomechanical tongue model to study speech motor control. Res Dev Biomech. 2003;1:49-64.

22. Proffitt WR, Kydd WL, Wilskie GH, Taylor DT. Intraoral pressure in a young adult group. J Dent Res. 1964;43:555-562.

23. Kydd WL. Quantitative analysis of forces of the tongue. J Dent Res. 1956;35(2):171-174.
24. Wallen TR. Vertically directed forces and malocclusion: a new approach. J Dent Res. 1974;53(5):1015-1022.

25. Dworkin JP, Aronson AE, Mulder DW. Tongue force in normals and in dysarthric patients with amyotrophic lateral sclerosis. J Speech Hear Res. 1980;23(4):828-837.

26. Sha BF, England SJ, Parisi RA, Strobel RJ. Force production of the genioglossus as a function of muscle length in normal humans. $J$ Appl Physiol. 1985;88(5):1678-1684.

27. Ruan WH, Chen MD, Gu ZY, Lu Y, Su JM, Guo Q. Muscular forces exerted on the normal deciduous dentition. Angle Orthod. 2005;75(5):785-790.

28. Blumen MB, de La Sota AP, Quera-Salva MA, Frachet B, Chabolle F, Lofaso F. Tongue mechanical characteristics and genioglossus muscle EMG in obstructive sleep apnoea patients. Respir Physiol Neurobiol. 2004;140(2):155-164.

29. Ono T, Hori K, Nokubi T. Pattern of tongue pressure on hard palate during swallowing. Dysphagia. 2004;19(4):259-264.

30. Kamal I. Normal standard curve for acoustic pharyngometry. Otolaryngol Head Neck Surg. 2001;124(3):323-330.

31. Avrahami E, Englender M. Relation between CT axial cross-sectional area of the oropharynx and obstructive sleep apnea syndrome in adults. AJNR Am J Neuroradiol. 1995;16(1):135-140.

32. Yucel A, Unlu M, Haktanir A, Acar M, Fidan F. Evaluation of the upper airway cross-sectional area changes in different degrees of severity of obstructive sleep apnea syndrome: cephalometric and dynamic CT study. AJNR Am J Neuroradiol. 2005;26(10):2624-2629.

33. Jung DG, Cho HY, Grunstein RR, Yee B. Predictive value of Kushida index and acoustic pharyngometry for the evaluation of upper airway in subjects with or without obstructive sleep apnea. J Korean Med Sci. 2004;19(5):662-667.

34. Mohsenin V. Gender differences in the expression of sleep-disordered breathing: role of upper airway dimensions. Chest. 2001;120(5):1442-1447.

35. Stone M. A Guide to Analysing Tongue Motion from Ultrasound Images. Baltimore, MD: University of Maryland; 2004.

36. South AR, Somers SM, Jog MS. Gum chewing improves swallow frequency and latency in Parkinson patients: a preliminary study. Neurology. 2010;74(15):1198-1202.

37. Horner RL, Shea SA, McIvor J, Guz A. Pharyngeal size and shape during wakefulness and sleep in patients with obstructive sleep apnea. QJM. 1989;72(268):719-735.

38. Schwab RJ, Pack AI, Gupta KB, et al. Upper airway and soft tissue structural changes induced by CPAP in normal subjects. Am J Respir Crit Care Med. 1996;154(4 Pt 1):1106-1116.

39. Athanasiou KA, Niederauer GG, Agrawal CM. Sterilization, toxicity, biocompatibility and clinical applications of polylactic acid/polyglycolic acid copolymers. Biomaterials. 1996;17(2):93-102.
Nature and Science of Sleep

\section{Publish your work in this journal}

Nature and Science of Sleep is an international, peer-reviewed, open access journal covering all aspects of sleep science and sleep medicine, including the neurophysiology and functions of sleep, the genetics of sleep, sleep and society, biological rhythms, dreaming, sleep disorders and therapy, and strategies to optimize healthy sleep. The manuscript
Dovepress

management system is completely online and includes a very quick and fair peer-review system, which is all easy to use. Visit http://www. dovepress.com/testimonials.php to read real quotes from published authors. 